\title{
CRIANZA DE FRANKLINIELLA WILLIAMSI HOOD (THYSANOPTERA: THRIPIDAE)
}

\author{
Menandro S. Ortiz
}

\begin{abstract}
RESUMEN
En el presente trabajo se presenta la descripción de un nuevo método de crianza de Thysanoptera, en este caso para Frankliniella williamsi Hood, las que pueden ser usados para estudios de ciclos biológicos de estos insectos.
\end{abstract}

Palabras claves: Crianza, Thysanoptera, Frankliniella.

\section{SUMMARY}

In the present paper is presented the descriptions of the new method of rearing of Thysanoptera, in this case for Frankliniella williamsi Hood. This method can used for biology studies of this insects.

Key words: Rearing, Thysanoptera, Frankliniella.

\section{INTRODUCCIÓN}

No son muchos los trabajos que existen sobre los ciclos biológicos de Thysanoptera, debido a una serie de dificultades que presentan para la crianza. Dentro de éstas dificultades se hallan el tamaño microscópico que tienen las especies que comprenden este grupo de insectos, los relativos movimientos rápidos cuando son adultos y sobre todo, la dificultad que se tiene en ofrecerles un microambiente para su desarrollo.

Entre los trabajos que tratan sobre este tema, se cita en primer lugar el de Bailey (1933) quien condujo la crianza de Caliotrhips fasciatus usando una hoja en el interior de un tubo de ensayo. La turgencia de la hoja la mantuvo colocando el peciolo de ésta en una placa petri con agua.

Faulkner (1954) y Harrison (1963) utilizaron tubos pequeños de vidrio sobre gradillas de madera para la crianza de Frankliniella occidentales y Frankliniella parvula.

Otro método que presenta Sakimura (1961) consiste en hacer uso de un "sandwich", es decir, una hoja entre dos microjaulas construidas en base a cartulina, espuma plástica, mallas y sostenidas por un clip en el haz y envés de la hoja.

En el presente trabajo se brinda una metodología de crianza modificada, que consiste en una serie de pasos, como son principalmente para la crianza individual y la oviposición.

\section{METODOLOGÍA}

1. Obtención de los ejemplares (crianza masal)

En un campo de maíz (Zea mays) se procede a examinar la parte envainante de las hojas inferiores de las plantas, preferentemente jóvenes. En dicha zona se hallan protegidos los ejemplares de Frankliniella williamsi Hood.

Con el uso de una bolsa de polietileno transparente se procede a la colecta de un número apreciable de éstos ejemplares. Si es posible, para mayor seguridad se puede sacrificar 1 ó 2 plantas pequeñas e introducirlas en dicha bolsa, la que luego se cierra para no permitir el escape de los ejemplares.

Inmediatamente se traslada al laboratorio, en donde ya se cuenta con plántulas de maíz, sembradas en macetas igualmente pequeñas para una mejor manipulación.

Con la ayuda de un pincel fino $\left(\mathrm{N}^{\circ} 0\right)$ se trasladan el máximo posible de thrips a dichas plántulas, con la finalidad de obtener oviposición, lo que prácticamente se logra observar a partir del día siguiente.

Se infiere que entre los ejemplares que provienen del campo existen formas sexualmente maduras. Además, de acuerdo a las observaciones efectuadas, las hembras son numéricamente dominantes. 
Los huevos son incrustados en los tejidos de las hojas, de modo longitudinal, entre las nervaduras (paralelas a éstas). Estas oviposiciones fueron observadas diariamente, hasta que ocurre la emergencia del primer estadío larval.

\section{Obtención del sustrato alimenticio}

Se trata de obtener el alimento diario de los thrips, para la crianza individual. Para este fin se realiza una siembra escalonada de maíz en macetas pequeñas. Las plantitas obtenidas tuvieron entonces diferentes edades.

Las macetas a usar son bastante pequeñas, en donde pueden desarrollar 5 ó 6 plántulas cuyo sustrato de enrraizamiento consiste en una mezcla de tierra (una parte) y arena de río (dos partes).

Antes de la siembra del maíz, se debe hacer germinar al grano, poniéndolo en una placa petri con papel toalla humedecido, durante 48 horas.

\section{Crianza individual}

Una vez obtenida los primeros estadíos larvales procedentes de la crianza masal, se procede a indiviadulizarlos, transfiriéndolos a envases de plástico con tapa hermética. Se codifica y anota la fecha de emergencia de cada uno de ellos, ya que no todos emergen en un mismo día. Para trabajos más analíticos se puede anotar incluso la hora.

El alimento que se les proporciona consiste en una porción de hoja cortadas con una tijera y colocados en el interior de los envases (jaulas) de crianza. Se recomienda colocar 2 porciones de hojas con la finalidad de asegurarles humedad y protección.

Este alimento debe ser cambiado a diario porque se deseca y se contamina con excrementos. Igualmente es recomendable cambiar los envases de crianza. El manejo de los ejemplares se realiza con el uso de finos pinceles.

Posteriormente continúa el desarrollo de cada uno de los ejemplares hasta cuando llegan a transformarse en adultos. Si bien las pupas no se alimentan, es necesario el cambio de hojas para asegurarles humedad.

\section{Obtención de huevos (oviposición)}

Una vez que han alcanzado el estado adulto, se les transfiere en forma individual sobre las plántulas de maíz, sembradas en envases similares a las jaulas de crianza individual, pero donde se les ha practicado agujeros en la base para que drene el agua de riego. El sustrato de la planta es el mismo para la obtención de alimento.

Para evitar la posible fuga del ejemplar obtenido en la crianza individual, se protege a la plántula con otro envase adecuado de plástico (pequeños reposteros), usándolos en forma invertida. A la tapa se le practica un agujero para que pueda penetrar la plántula y al piso del envase (ahora techo) se le practica un agujero más grande y luego se le cubre con tul para permitir la aereación.

La transferencia del ejemplar, como en los otros casos se realiza con un fino pincel. Para este caso y los anteriores, se puede facilitar el trabajo, inactivándolos con el uso del $\mathrm{CO}_{2}$ por un tiempo prudencial. Incluso es muy útil para realizar la determinación de sexos, aunque como ya se ha señalado, priman numéricamente las hembras.

En éstas condiciones, los ejemplares tienen alimento continuo y sobre todo, sustrato de oviposición adecuado, para las observaciones correspondientes.

\section{RESULTADOS}

Con el método presentado fue posible observar el desarrollo biológico de Frankliniella williamsi Hood, habiéndose obtenido de manera completa cada uno de los estados de desarrollo de este grupo de insectos: huevo, larva I, larva II, prepupa, pupa y adultos. Sólo se consigna datos preliminares, ya que únicamente se trabajó con la primera generación, proveniente de campo; y que ha servido para detallar el método de crianza. Durante el experimento hubo un cierto porcentaje de mortalidad, lo que es de suceder hasta la adaptación de la población a las condiciones ambientales de laboratorio. Preliminarmente se cuenta con los siguientes datos:

\begin{tabular}{|c|c|c|c|c|c|}
\hline Estados de desarrollo & Huevo & Larva I & Larva II & Prepupa & Pupa \\
\hline Días & 7 & 3 & 4 & 2 & 3 \\
\hline
\end{tabular}

\section{LITERATURA CITADA}

Bailey, S.F. 1933. The Biology of the Bean Thrips. Hilgardia 7:467-522

Faulkner, L.R. 1954. Economics Thrips of Southern New Mexico. New Mexico Coll. Agr. \& Mech. Arts, Agr. Exp. Sta.. Bull. 387, 26 pp.

Harrison, J.C. 1963. Notes on the Biology of the Banana Flower Thrips, Frankliniella parvula, in the Dominican Republic (Thysanoptera: Thripidae). Ann. Ent. Soc. Amer. 56: 664-666.

Sakimura, K. 1961. Techniques for Handling Thrips in Transmission Experiments with the Tomato Spotted Wilt Virus. Pl. Dis. Reptr. 45: 766-771 